\title{
Performance of community health workers and associated factors in a rural community in Wakiso district, Uganda
}

\author{
David Musoke ${ }^{1}$, Rawlance Ndejjo ${ }^{1}$, Edwinah Atusingwize ${ }^{1}$, Trasias Mukama ${ }^{1}$, \\ Charles Ssemugabo ${ }^{1}$, Linda Gibson ${ }^{2}$
}

1. Department of Disease Control and Environmental Health, School of Public Health, Makerere University College of Health Sciences, Kampala, Uganda.

2. School of Social Sciences, Nottingham Trent University, Nottingham, UK.

\section{Emails:}

DM: dmusoke@musph.ac.ug; RN: rndejjo@musph.ac.ug; EA: eatusingwize@musph.ac.ug; TM: stanmukama@musph.ac.ug; CS: cssemugabo@musph.ac.ug; LG: linda.gibson@ntu.ac.uk

\begin{abstract}
Background: Community health workers (CHWs) continue to play a crucial role in supporting health service delivery globally. Several CHW programmes around the world face vast challenges which affect their performance.

Objectives: This study assessed the performance of CHWs and associated factors in a rural community in Wakiso district, Uganda.

Methods: This was a cross-sectional study that employed a structured questionnaire to collect quantitative data from 201 CHWs in Wakiso district. The main study variable was CHW performance based on various roles carried out by CHWs. Multivariable logistic regression in STATA was used to establish the predictors of CHW performance.

Results: Only 40 (19.9\%) of the CHWs had a high performance which was associated with having attended additional / refresher trainings [AOR=12.79 (95\% CI: 1.02-159.26)], and having attained secondary level education and above [AOR=3.93 (95\% CI: 1.17-13.24)]. CHWs who were married [AOR $=0.29$ (95\% CI: 0.09-0.94)] were less likely to perform highly. Among CHWs who had received essential medicines for treatment of childhood illnesses, the majority $90.3 \%(112 / 124)$ had experienced stock-outs in the 6 months preceding the study. Despite the majority of CHWs, $198(98.5 \%)$, stating that being motivated was very important in their work, only $91(45 \%)$ said that they were motivated.

Conclusion: Additional / refresher trainings are necessary to enhance performance of CHWs. In addition, level of education should be considered while selecting CHWs. The health system challenges of low motivation of CHWs as well as stock-out of medicines need to be addressed to support their work.

Keywords: Community health workers, performance, motivation, satisfaction, stock-outs, village health teams, Uganda.

DOI: https://dx.doi.org/10.4314/ahs.v19i3.55

Cite as: Musoke D, Ndejjo R, Atusingwize E, Mukama T, Ssemugabo C, Gibson L. Performance of community health workers and associated factors in a rural community in Wakiso district, Uganda. Afri Health Sci. 2019;19(3): 2784-2797. bttps:// dx.doi.org/10.4314/abs.v19i3.55
\end{abstract}
Corresponding author:
David Musoke, Department of Disease Control and Environmental Health, School of Public Health, Makerere University College of Health Sciences, Kampala, Uganda.
Telephone: +256312263158; fax: +256414531807 Email: dmusoke@musph.ac.ug

\section{Background}

The human resources for health crisis continues to plague health systems in low-and middle-income countries ${ }^{1}$. Community health workers (CHWs) have supported health systems in the provision of primary health care in several parts of the world for decades ${ }^{2}$. A community health worker has been defined as any health worker involved in functions related to health care delivery; trained to some extent in the context of their roles; and without any formal professional or paraprofessional education ${ }^{3}$.

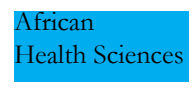

(C) 2019 Musoke et al. Licensee African Health Sciences. This is an Open Access article distributed under the terms of the Creative commons Attribution License (https://creativecommons.org/licenses/BY/4.0), which permits unrestricted use, distribution, and reproduction in any medium, provided the original work is properly cited. 
Community health workers may be paid or unpaid depending on the country programme in which they are working, and play a distinct role that can neither be done by professional health workers or the community itself ${ }^{4}$. CHWs typically offer a wide range of community based services including assisting in child birth, counseling on breastfeeding, management of uncomplicated childhood illnesses, mobilisation for public health interventions, and health education ${ }^{5}$. The significance of CHWs to the improvement of health of populations ${ }^{2,5}$ is for example related to their contribution to cost reduction and effectiveness of interventions in many developing countries including Uganda ${ }^{6,7}$.

In Uganda, access to healthcare remains a challenge particularly in rural areas. In 2001, the Ministry of Health $(\mathrm{MOH})$ introduced a CHW programme known as the Village Health Team (VHT) strategy as part of the Uganda National Minimum Health Care Package (UNMHCP) $)^{8,9}$. The VHT comprises of community volunteers who are selected from within their communities to provide health information, primary healthcare support and appropriate linkages to health services. Incorporated into the health system as Health Centre I, VHTs are the first point of contact for healthcare delivery in the community and participate in community based primary health care programmes across the country ${ }^{10}$.

The implementation of the VHT strategy in Uganda has not been satisfactory. As of November 2009, VHTs were established in $75 \%$ of the districts but only $31 \%$ had them trained in all villages ${ }^{11}$ mainly because of inadequate funding. However, where VHTs are functional within the country, they have contributed to increasing health awareness, demand and utilisation of health services, and significantly led to decongestion at health facilities as they treat minor illnesses in a timely manner ${ }^{12}$. Globally, CHWs have further helped to enhance community participation in local health programmes, promote adoption of healthy behaviours, and increase access to a range of health services ${ }^{5,13,14}$.

Despite the contribution of CHWs to health systems, problems exist regarding their level of performance and retention. High levels of attrition of up to $77 \%$ have been reported where these CHWs are volunteers ${ }^{15}$ and in most cases, even those who stay on job do not perform optimally ${ }^{2}$. Supportive supervision, recognition, training, equipment and supplies have been identified to be critical elements affecting the level of activity and retention of CHWs ${ }^{15,16,17,18}$. However, a situation analysis of VHTs in Uganda found major shortfalls in these critical elements ${ }^{19}$. Exploring ways of improving and sustaining the VHT programme remains a priority for $\mathrm{MOH}^{20}$. The current status of the performance of the VHT programme in Uganda and Ssisa sub-county, Wakiso district in particular is not precisely known. This therefore necessitated the study to assess performance of CHWs and associated factors in Ssisa sub-county. This study was carried out as part of a baseline survey of a project aimed at strengthening the CHW programme in Ssisa sub-county by providing a coherent, structured and standardised training, supervision and motivation package.

\section{Methods}

\section{Study design, participants and data collection}

The study, carried out in 2014, was cross-sectional in design and involved collecting quantitative data. The data presented is from a baseline survey conducted in the area in preparation for implementation of a project to strengthen the capacity of $\mathrm{CHWs}^{21}$. The participants of the study were CHWs including both those involved (usually 2 per village) and not involved in integrated community case management of childhood illnesses (iCCM) of malaria, diarrhoea and pneumonia (usually 2 per village) as selected by their local authorities. The CHWs not involved in iCCM specifically carry out health education, household visiting, community mobilisation for public health interventions, and other related activities. Data were collected using a structured questionnaire that was developed with reference to existing literature ${ }^{15}$ and had four sections. The first section collected data on socio-demographic characteristics such as age, gender, level of education, and duration of working as a CHW. The second section obtained information on the status of the CHW programme including recruitment, training, roles and responsibilities, supervision and motivation. The third and fourth sections assessed knowledge and practices about malaria and diarrhoea management respectively which were within the scope of the study. This paper presents data from sections one and two. Two research assistants, who had been trained by the research team, collected data and were closely supervised during the entire data collection process. The CHWs were found at their homes during data collection. 


\section{Study area and sampling}

The study was conducted in Ssisa sub-county, Wakiso district located in the Central region of Uganda. In 2014, Ssisa sub-county had a population of 94,238, 23,992 households and average household size of $3.8^{22}$, and is primarily rural with some villages in peri-urban settings. The main income generating activities in the area are agriculture, trade, sand mining and stone quarrying. Part of Lake Victoria, the largest freshwater body in Africa, is found in Wakiso district hence some of the population is involved in fishing. Ssisa sub-county has two main government health facilities that supervise CHWs: a health centre IV (which offers emergency surgical care, outpatient and inpatient services) and a health centre III (which mainly provides out-patient care and out-reach services). The sub-county had 64 villages and each was mandated to have 4 CHWs hence 256 were expected to be found in the area. The CHWs are supported by Parish Coordinators who together with the $\mathrm{CHW}$ focal person at the health facilities supervise them. Each parish in the sub-county has 2 Coordinators who collect monthly reports from the CHWs then deliver them to the health facility. All CHWs in the area are involved in household visiting, health education, community mobilisation, as well as serving as the first contact of the community with the health system. Although each CHW in Uganda was initially expected to serve approximately 25 households, most of those in Ssisa sub-county serve a higher number due to the high population in the area. Wakiso district has the largest population $(2,007,700)$ in the country ${ }^{22}$ and neighbours Kampala, Uganda's capital city. Part of Lake Victoria, the largest freshwater body in Africa, is found in Wakiso district hence some of the population is involved in fishing. All CHWs in the sub-county were involved in the study. These CHWs were identified through local leaders and community mobilisers in the study villages and had worked for more than 6 months in the area.

\section{Data analysis}

Data was entered in Epidata version 3.02 (EpiData Association, Denmark) and analysed in STATA version 12.0 (Stata Corp, Texas, USA) statistical software. The outcome variable for the study was CHW performance which had two categories - high and low. This variable was constructed using 8 questions which were:

whether CHWs carried out home visits (Yes / No); the average number of home visits they carried out in a month (above or below average);

home visits carried out in the previous month (above or below average);

- $\quad$ whether they carried out health education (Yes / No);

- $\quad$ average number of health education sessions carried out in previous month (above or below average);

whether they used a register (Yes / No) and whether it was completely filled (Yes / No);

and whether they compiled information from record books into monthly reports (Yes / No).

Each of the questions was assigned a score of 1 whenever a CHW reported "Yes" to the "Yes / No" questions, or was "above average" to the other questions, and a total score for each CHW was obtained. From this assessment, a total maximum score of 8 was possible if a CHW reported "Yes" to all the "Yes / No" questions, and was "above average" to all other questions. CHWs were categorised as having had high performance if their total score was 6 and above, and low performance if the score was less than 6 forming a binary outcome variable. Generating the variables for scoring was informed by the roles of CHWs as per the Uganda Ministry of Health guidelines and other existing literature $e^{2,10,19,23}$ and scoring was guided by previous studies ${ }^{24,25}$. Bivariate analysis was carried out to ascertain the relationship between the outcome and exploratory variables of socio-demographic characteristics, recruitment, training, supervision and motivation. To obtain the independent predictors of performance among CHWs, all variables from the bivariate analysis were examined simultaneouly in a multivariable logistic regression model using the backward elimination method. Odds ratios and p-values were used as measures of association with a p-value of less than 0.05 considered for a statistically significant relationship at 95\% confidence level.

\section{Ethical considerations}

The study received ethical approval from Makerere University School of Public Health Higher Degrees, Research, and Ethics Committee (protocol 286), and was registered at the Uganda National Council for Science and Technology (HS 1790). All participants provided written informed consent before their involvement in the study. Consent to participate in the research, which was 
obtained by research assistants in the local language (Luganda), was sought after clearly explaining to participants the purpose of the study as well as the benefits and risks involved in their participation.

\section{Results}

\section{Socio-demographic characteristics of participants}

This study involved all the $201 \mathrm{CHWs}$ found in the sub-county, a presence of $78.5 \%$ of the expected number (256). More than half of the CHWs 110 (54.7\%) were above 40 years of age, and the majority were female 152 (75.6\%), Christians 186 (92.5\%), married 147 (73.1\%), and their households earned less than 50 US dollars per month $159(79.1 \%)$. The majority of participants had served as a CHW for four years and below 161 (80.1\%), and almost all $196(97.5 \%)$ owned a mobile phone. Additionally, most $\mathrm{CHWs}$ served more than 50 households $124(61.7 \%)$, and $129(64.2 \%)$ of them were involved in iCCM. There were no statistically significant differences between male and female CHWs as regards their socio-demographic characteristics (Table 1).

Table 1: Socio-demographic characteristics of participants

\begin{tabular}{|c|c|c|c|c|}
\hline Characteristic & Total (\%) & Males (\%) & Females $(\%)$ & p-value \\
\hline Overall & $201(100.0)$ & $49(24.4)$ & $152(75.6)$ & \\
\hline Age in years [Mean (SD)] & $42.7( \pm 10.1)$ & $41.7( \pm 11.2)$ & $43.1( \pm 9.7)$ & \\
\hline $24-40$ & $91(45.3)$ & $26(53.1)$ & $65(42.8)$ & \\
\hline$>40$ & $110(54.7)$ & $23(46.9)$ & $87(57.2)$ & 0.208 \\
\hline \multicolumn{5}{|l|}{ Religion } \\
\hline Christians & $186(92.5)$ & $45(91.8)$ & $141(92.8)$ & \\
\hline Muslims & $15(7.5)$ & $4(8.2)$ & $11(7.2)$ & 0.830 \\
\hline \multicolumn{5}{|l|}{ Education level } \\
\hline Primary & $75(37.3)$ & $14(28.6)$ & $61(40.1)$ & \\
\hline Secondary and above & $126(62.7)$ & $35(71.4)$ & $91(59.9)$ & 0.146 \\
\hline \multicolumn{5}{|l|}{ Marital status } \\
\hline Single* & $54(26.9)$ & $8(16.3)$ & $46(30.3)$ & \\
\hline Married & $147(73.1)$ & $41(83.7)$ & $106(69.7)$ & 0.056 \\
\hline \multicolumn{5}{|l|}{ Occupation } \\
\hline Agriculture & $110(54.7)$ & $25(51.0)$ & $85(55.9)$ & \\
\hline Business & $47(23.4)$ & $12(24.5)$ & $35(23.0)$ & \\
\hline Others (housewife, civil servant, casual labourer) & $44(21.9)$ & $12(24.5)$ & $32(21.0)$ & 0.820 \\
\hline \multicolumn{5}{|l|}{ Average monthly household income (US dollars) } \\
\hline$\leq 50$ & $159(79.1)$ & $36(73.5)$ & $123(80.9)$ & \\
\hline$>50$ & $42(20.9)$ & $13(26.5)$ & $29(19.1)$ & 0.265 \\
\hline \multicolumn{5}{|l|}{ Duration lived in area (years) } \\
\hline$\leq 25$ & $93(46.3)$ & $18(36.7)$ & $75(49.3)$ & \\
\hline$>25$ & $108(53.7)$ & $31(63.3)$ & $77(50.7)$ & 0.124 \\
\hline \multicolumn{5}{|l|}{ Duration in CHW work (years) } \\
\hline$\leq 4$ & $161(80.1)$ & $41(83.7)$ & $120(78.9)$ & \\
\hline$>4$ & $40(19.9)$ & $8(16.3)$ & $32(21.1)$ & 0.471 \\
\hline \multicolumn{5}{|l|}{ Owned a mobile phone } \\
\hline Yes & $196(97.5)$ & $49(100.0)$ & $147(96.7)$ & \\
\hline No & $5(2.5)$ & $0(0.0)$ & $5(3.3)$ & 0.199 \\
\hline \multicolumn{5}{|l|}{ Number of households served } \\
\hline$\leq 50$ & $77(38.3)$ & $16(32.6)$ & $61(40.1)$ & \\
\hline$>50$ & $124(61.7)$ & $33(67.3)$ & $91(59.9)$ & 0.349 \\
\hline \multicolumn{5}{|l|}{ Health facility of attachment } \\
\hline Kajjansi HC IV & $81(40.3)$ & $22(44.9)$ & $59(38.8)$ & \\
\hline Nakawuka HC III & $120(59.7)$ & $27(55.1)$ & $93(61.2)$ & 0.450 \\
\hline \multicolumn{5}{|l|}{ Involved in iCCM } \\
\hline Yes & $129(64.2)$ & $26(53.1)$ & $103(67.8)$ & \\
\hline No & $72(35.8)$ & $23(46.9)$ & $49(32.2)$ & 0.062 \\
\hline
\end{tabular}

* Includes those who were widowed, separated or divorced. 


\section{Community health worker performance}

The majority of CHWs carried out home visits 176 $(87.6 \%)$ and community health education 180 (89.6\%).
In the month preceding the study, the average number of home visits, health education sessions, and children treated for malaria, diarrhoea and pneumonia by each $\mathrm{CHW}$ were $7.8,1.2$ and 6.5 respectively (Table 2 ).

Table 2: Community health worker performance of selected roles and responsibilities

\begin{tabular}{|c|c|}
\hline Roles and responsibilities $(\mathrm{n}=\mathbf{2 0 1})$ & Frequency $(\%)$ \\
\hline \multicolumn{2}{|l|}{ Carried out home visiting } \\
\hline Yes & $176(87.6)$ \\
\hline No & $25(12.4)$ \\
\hline Average number of home visits conducted in a month & Mean $(\mathrm{SD})=14.9( \pm 16.7)$ \\
\hline$\leq 10$ & $115(57.2)$ \\
\hline$\geq 10$ & $86(42.8)$ \\
\hline Average number of household visits made in previous month $(n=176)$ & Mean $(\mathrm{SD})=7.8( \pm 15.5)$ \\
\hline None & $61(34.6)$ \\
\hline$\leq 10$ & $86(48.9)$ \\
\hline$>10$ & $29(16.5)$ \\
\hline \multicolumn{2}{|l|}{ Carried out community health education } \\
\hline Yes & $180(89.6)$ \\
\hline No & $21(10.4)$ \\
\hline Number of health education sessions carried out in previous month $(n=180)$ & Mean $(\mathrm{SD})=1.2( \pm 2.6)$ \\
\hline None & $76(42.2)$ \\
\hline$\leq 2$ & $87(48.3)$ \\
\hline$\geq 2$ & $17(9.4)$ \\
\hline \multicolumn{2}{|l|}{ Possessed and used register $(\mathrm{n}=156)$} \\
\hline Yes & $149(95.5)$ \\
\hline No & $7(4.5)$ \\
\hline \multicolumn{2}{|l|}{ Register completely filled $(n=149)$} \\
\hline Yes & $113(75.8)$ \\
\hline No & $36(24.2)$ \\
\hline \multicolumn{2}{|l|}{ Compiled information from record books into monthly reports } \\
\hline Yes & $64(31.8)$ \\
\hline No & $137(68.2)$ \\
\hline $\begin{array}{l}\text { Average number of children treated for malaria, diarrhoea and } \\
\text { pneumonia monthly among those involved in } \operatorname{iCCM}(n=129)\end{array}$ & Mean $(\mathrm{SD})=34.8( \pm 20.8)$ \\
\hline$\leq 40$ & $107(83.0)$ \\
\hline$>40$ & $22(17.0)$ \\
\hline $\begin{array}{l}\text { Number of children treated for malaria, diarrhoea and pneumonia } \\
\text { in previous month among those involved in iCCM }(n=129)\end{array}$ & Mean $(\mathrm{SD})=6.5( \pm 7.3)$ \\
\hline None & $55(42.6)$ \\
\hline$\leq 10$ & $55(42.6)$ \\
\hline$>10$ & $19(14.7)$ \\
\hline
\end{tabular}


Socio-demographic characteristics associated with community health worker performance

Using our performance indicator, $40(19.9 \%)$ of the CHWs had high performance overall. We compared CHWs that had high performance against those with low performance (comparison group). At bivariate analysis,
CHWs who had attained secondary level education and above [COR=2.39, (95\% CI: 1.07-5.36), $\mathrm{p}=0.034$ ] were more likely to have performed highly while those who were not engaged in iCCM [COR $=0.11$ (95\% CI: 0.03 $0.36), \mathrm{p}<0.001]$ registered low performance when compared with their counterparts (Table 3).

Table 3: Associations between socio-demographic characteristics and community health worker performance

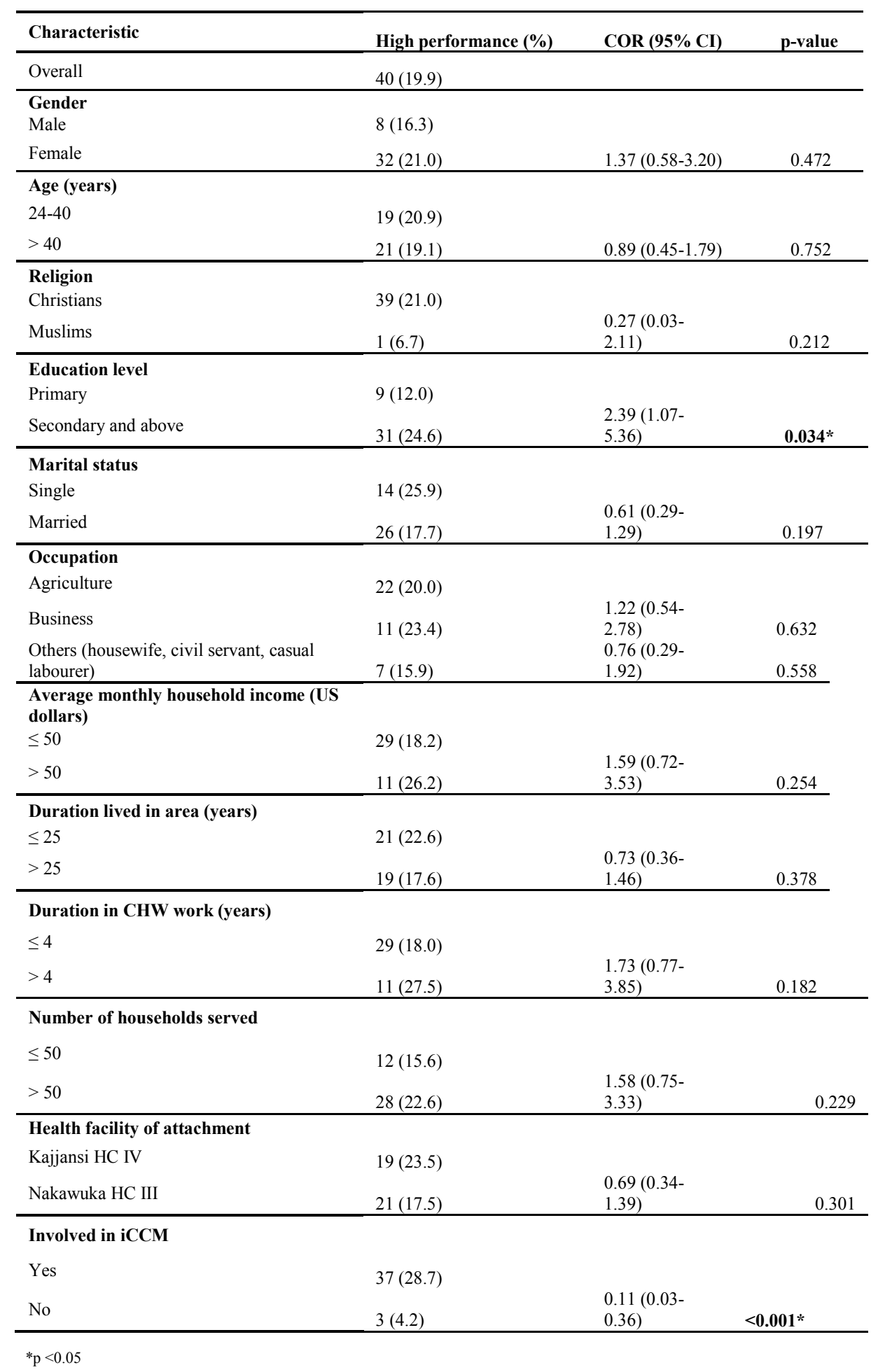


Relationship between community health worker recruitment, training, supervision and motivation with performance

There was a statistically significant relationship between having attended additional / refresher trainings $[\mathrm{COR}=12.54 \quad(95 \%$ CI: 2.92-53.8), $\mathrm{p}=0.001]$ among
CHWs and high performance. In addition, although not statistically significant, CHWs who were selected by local leaders, fellow CHWs and health workers [COR $=2.05$ (95\% CI: 0.85-4.92), $\mathrm{p}=0.110]$, and those who reported high motivation $[\mathrm{COR}=2.04$ (95\% CI: 0.89-4.65), $\mathrm{p}=0.090]$ were more likely to have performed well (Table 4).

Table 4: Association between recruitment, training, supervision and motivation with $\mathrm{CHW}$ performance

\begin{tabular}{|c|c|c|c|}
\hline Characteristic & High performance $(\%)$ & $\operatorname{COR}(95 \% \mathrm{CI})$ & p-value \\
\hline \multicolumn{4}{|l|}{ Recruitment } \\
\hline $\begin{array}{l}\text { Selected by community } \\
\text { Selected by local leaders, fellow } \\
\text { CHWs and health workers }\end{array}$ & $31(18.0)$ & $2.05(0.85-4.92)$ & 0.110 \\
\hline \multicolumn{4}{|c|}{ Attended additional / refresher trainings } \\
\hline No & $2(3.0)$ & & \\
\hline Yes & $38(28.1)$ & $12.54(2.92-53.8)$ & 0.001* \\
\hline \multicolumn{4}{|c|}{ Knew 5 or more roles and responsibilities } \\
\hline No & $14(15.4)$ & & \\
\hline Yes & $26(23.6)$ & $1.70(0.83-3.49)$ & 0.147 \\
\hline \multicolumn{4}{|c|}{ Were supervised in the previous month $(n=198)$} \\
\hline No & $13(17.1)$ & & \\
\hline Yes & $27(22.1)$ & $1.38(0.66-2.87)$ & 0.393 \\
\hline \multicolumn{4}{|l|}{ Current motivation } \\
\hline Low motivation & $10(12.8)$ & & \\
\hline High motivation & $21(23.1)$ & $2.04(0.89-4.65)$ & 0.090 \\
\hline
\end{tabular}

\section{Predictors of $\mathrm{CHWs}$ performance}

When all variables were examined simultaneously in the same model and confounders of gender, age, education level, marital status, occupation, household income, duration in CHW work and involvement in iCCM controlled for, CHWs who had attended additional / refresher trainings $[\mathrm{AOR}=12.79$ (95\% CI: 1.02-159.26), $\mathrm{p}=0.048]$ were over 12 times more likely to have registered higher per- formance compared with their counterparts. Similarly, CHWs who had attained secondary level education and above $[\mathrm{AOR}=3.93$ (95\% CI: 1.17-13.24), $\mathrm{p}=0.027$ ] were over three times more likely to have performed highly when compared to those who had only primary education. On the other hand, CHWs who were married $[\mathrm{AOR}=0.29$ (95\% CI: 0.09-0.94), $\mathrm{p}=0.039]$ were less likely to have been high performers (Table 5 ). 
Table 5: Independent predictors of CHW performance

\begin{tabular}{|c|c|c|}
\hline Characteristics & $\operatorname{AOR}(95 \% \mathrm{CI})$ & p-value \\
\hline \multicolumn{3}{|l|}{ Recruitment } \\
\hline \multicolumn{3}{|l|}{ Selected by community } \\
\hline Selected by local leaders, fellow CHWs and health workers & $2.02(0.45-9.05)$ & 0.357 \\
\hline \multicolumn{3}{|l|}{$\begin{array}{l}\text { Received any additional or refresher trainings } \\
\text { No }\end{array}$} \\
\hline Yes & $12.79(1.02-159.26)$ & 0.048* \\
\hline \multicolumn{3}{|l|}{ Knew 5 or more roles and responsibilities } \\
\hline Yes & $1.25(0.39-3.98)$ & 0.710 \\
\hline \multicolumn{3}{|l|}{$\begin{array}{l}\text { Were supervised in the last month } \\
\text { No }\end{array}$} \\
\hline Yes & $0.47(0.16-1.37)$ & 0.166 \\
\hline \multicolumn{3}{|l|}{ Current motivation } \\
\hline High motivation & $3.35(0.55-20.42)$ & 0.190 \\
\hline \multicolumn{3}{|l|}{ Gender } \\
\hline \multicolumn{3}{|l|}{ Male } \\
\hline Female & $0.48(0.14-1.64)$ & 0.241 \\
\hline \multicolumn{3}{|l|}{$\begin{array}{l}\text { Age (years) } \\
24-40\end{array}$} \\
\hline$>40$ & $1.40(0.42-4.66)$ & 0.581 \\
\hline \multicolumn{3}{|l|}{ Education level } \\
\hline Secondary and above & $3.93(1.17-13.24)$ & $0.027 *$ \\
\hline \multicolumn{3}{|l|}{ Marital status } \\
\hline \multicolumn{3}{|l|}{ Single } \\
\hline Married & $0.29(0.09-0.94)$ & 0.039* \\
\hline \multicolumn{3}{|l|}{ Occupation } \\
\hline \multicolumn{3}{|l|}{ Agriculture } \\
\hline Business & $1.99(0.43-9.24)$ & 0.379 \\
\hline Others (housewife, civil servant, casual labourer) & $0.67(0.09-4.48)$ & 0.677 \\
\hline \multicolumn{3}{|l|}{$\begin{array}{l}\text { Average monthly household income (US dollars) } \\
\leq 50\end{array}$} \\
\hline$>50$ & $0.80(0.25-2.59)$ & 0.710 \\
\hline \multicolumn{3}{|l|}{ Duration lived in area (years) } \\
\hline$>25$ & $0.68(0.21-2.20)$ & 0.520 \\
\hline \multicolumn{3}{|l|}{ Duration in CHW work (years) } \\
\hline \multicolumn{3}{|l|}{$\leq 4$} \\
\hline$>4$ & $1.14(0.39-3.32)$ & 0.809 \\
\hline \multicolumn{3}{|l|}{$\begin{array}{l}\text { Number of households served } \\
\leq 50\end{array}$} \\
\hline$>50$ & $0.82(0.26-2.56)$ & 0.735 \\
\hline \multicolumn{3}{|l|}{ Health facility of attachment } \\
\hline \multicolumn{3}{|l|}{ Kajjansi HC IV } \\
\hline Nakawuka HC III & $0.71(0.08-6.32)$ & 0.759 \\
\hline \multicolumn{3}{|l|}{ Involved in iCCM } \\
\hline \multicolumn{3}{|l|}{ Yes } \\
\hline No & $0.19(0.02-1.38)$ & 0.100 \\
\hline
\end{tabular}

Incentives, motivation and satisfaction of community health workers

The majority of CHWs 198 (98.5\%) stated that being motivated was very important in their work although only $91(45 \%)$ reported being motivated at the time of the study. Most of the participants were satisfied with their work 186 (92.5\%) and fellow CHWs 173 (86.1\%), and least satisfied with their working conditions 8 (4.0\%). Despite recognising that both financial $200(99.5 \%)$ and non-financial $200(99.5 \%)$ incentives were important, most CHWs 173 (86.1\%) preferred finances as a motivational avenue (Figure 1).

\section{Equipment, supplies and their stock-outs}

Most participants $124(61.7 \%)$ had received essential medicines among whom majority 112 (90.3\%) had experienced stock-outs in the 6 months preceding the study (Table 6). 


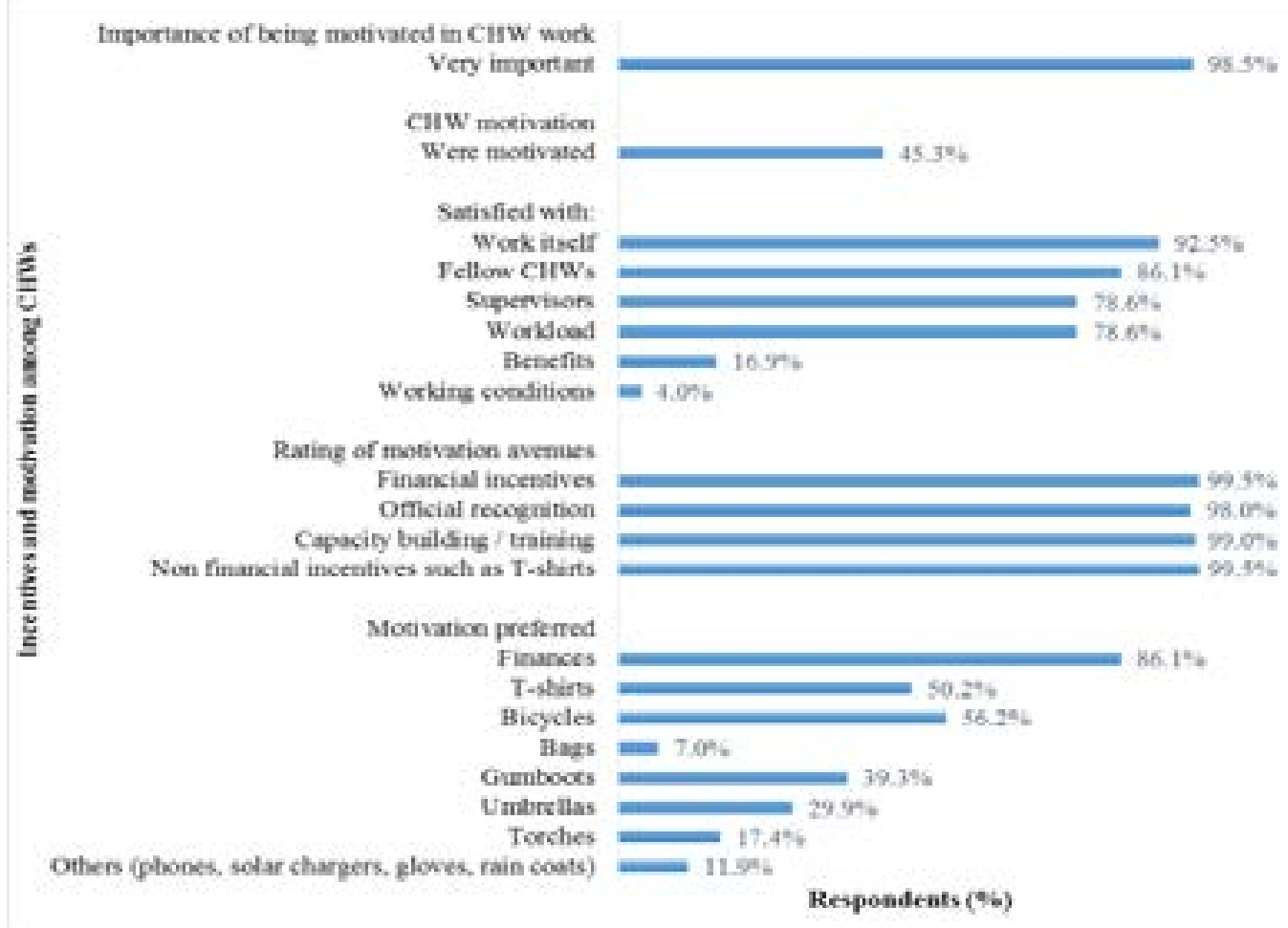

Figure 1: Incentives, motivation and satisfaction of CHWs

Table 6 Equipment and supplies provided to community health workers and their stock-outs

\begin{tabular}{llll}
\hline Equipment and supplies & Had ever received & $\begin{array}{l}\text { Currently } \\
\text { had }\end{array}$ & $\begin{array}{l}\text { Experienced stock-outs } \\
\text { in previous 6 months }\end{array}$ \\
\hline Registers & $189(94.0)$ & $186(98.4)$ & $3(1.6)$ \\
Storage boxes & $128(63.7)$ & $127(99.2)$ & $1(0.8)$ \\
Report books & $148(73.6)$ & $144(96.6)$ & $5(3.4)$ \\
Job aids and information, education and & & & \\
communication materials & $176(87.6)$ & $164(93.2)$ & $14(7.9)$ \\
Referral forms & $122(60.7)$ & $110(90.2)$ & $13(10.7)$ \\
Essential medicines & $124(61.7)$ & $19(15.3)$ & $112(90.3)$ \\
Timer & $121(60.2)$ & $55(45.4)$ & $65(54.2)$ \\
Middle-upper arm circumference strips & $118(58.7)$ & $114(96.6)$ & $5(4.2)$ \\
\hline
\end{tabular}




\section{Discussion}

This study explored performance of CHWs and associated factors in a rural community in Uganda. Performance, which was rated as either high or low, was measured based on the roles of CHWs including home visiting, conducting health education, record keeping, reporting and treatment of childhood illnesses. Only one in five of the CHWs had a higher performance. Factors associated with CHW performance were: receiving additional / refresher trainings, attainment of secondary level education and above, and not being married. CHWs highlighted that motivation with financial or non-financial incentives as well as recognition was important to their work. However, they faced challenges of stock-out of essential medicines and other supplies. In addition, CHWs' satisfaction with working conditions was very low.

Worldwide, CHW programmes have more females than males $^{2,26,27}$ similar to our study findings. This is understandable as women usually have more time and are more willing to engage in voluntary work in the Ugandan context. On the other hand, most men are more involved in income generating activities to be able to financially support their families. In our study, the majority of CHWs $(61.7 \%)$ served more than 50 households which is beyond the recommended number by $\mathrm{MOH}$ where each one is supposed to serve 25 to 30 households $^{28}$. This could be explained by the few CHWs available in many Ugandan communities for the large population. Indeed, with a high population growth rate of $3.0^{29}$, Uganda's population is increasing considerably without the recommended number of CHWs per village having changed since the CHW programme inception in 2001. Moreover, we found that only $201 \mathrm{CHWs}$ were available to serve a catchment meant for 256. In our study, almost all CHWs (97.5\%) owned mobile phones presenting potential for promoting community health using $\mathrm{m}$-health which can be explored by $\mathrm{MOH}$ and development partners. The role of mobile phones in improving access to maternal and newborn health information ${ }^{30}$ and promoting $\mathrm{iCCM}^{31}$ has been demonstrated by previous Ugandan studies.

CHWs perform a number of roles in health promotion as shown in previous studies ${ }^{2,32}$. In Uganda, the major roles of CHWs include: conducting home visits, health education, mobilising the community for public health interventions, and treatment of children for malaria, di- arrhoea and pneumonia. Our study revealed that the majority of CHWs $(87.6 \%)$ were engaged in home visiting and had carried out an average of 15 visits in the previous month. Home visits have been shown to improve the health seeking behaviours of communities in studies carried out in Uganda $a^{30,33}$. Indeed, based on the status of households during home visits, CHWs educate members on how to improve their conditions including water, sanitation and hygiene. Our study found that most CHWs $(89.6 \%)$ carried out health education sessions in the community geared towards increasing individuals' capacity to promote and improve their health. Much as most CHWs $(64.2 \%)$ were involved in treatment of children suffering from malaria, diarrhoea and pneumonia, very few children (average of 6.5) had been treated in the month preceding the study. The low treatment of children could have been due to fewer numbers of sick children but more plausibly stock-out of essential medicines and other necessary supplies as established in our study, and reported elsewhere ${ }^{34}$.

There was low performance of CHWs $(80.1 \%)$ in this study despite the VHT programme in Uganda having been in existence since 2001. Similarly, studies in Bangladesh and Uganda registered a low level of performance of CHWs particularly in maternal and child health ${ }^{16,25}$. Among the factors associated with having higher performance among CHWs in our study was attaining secondary level education and above $(\mathrm{AOR}=3.93$ [95\% CI: 1.17-13.24]). In the selection criteria of CHWs in Ugan$\mathrm{da}$, individuals should be able to read and write without necessarily considering the actual level of education ${ }^{29}$. Level of education increases CHWs competence in keeping records, using job aids, and ability to counsel clients. In addition, CHWs with higher literacy are more likely to easily learn and enhance their knowledge and skills on health issues in the community. Indeed, studies carried out in Nigeria, Kenya and India observed that more literate CHWs could learn and enhance their skills hence deliver better services ${ }^{35,36,37,38}$. Therefore, level of education should be considered in the selection of CHWs so as to enhance their performance.

In our study, CHWs who had received additional or refresher trainings were more likely to have performed highly. It has been reported that continuous training leads to better performance of $\mathrm{CHWs}^{39}$. This is understandable as trainings increase knowledge and skills of CHWs 
in performing their roles as highlighted in several studies $^{33,40,41}$. Although the $\mathrm{MOH}$ guidelines recommend routine refresher trainings of $\mathrm{CHWs}^{28}$, they are carried out infrequently. There is therefore need for regular continuous training of CHWs for programmes to optimally benefit from their services in communities. A recent scoping review emphasizes the importance of design, delivery, monitoring and sustainability of ongoing training programmes from a health systems strengthening perspective to increase their impact ${ }^{42}$. On the other hand, married respondents in our study were less likely to perform highly contrary to findings of a study conducted in Kenya which reported otherwise ${ }^{38}$. In the Kenyan study, it was argued that married CHWs are more likely to have support with domestic duties at home leaving them with more time to engage in $\mathrm{CHW}$ work. However, marriage usually comes with extra responsibilities that may demand more time from the CHWs compared to when they are not married and thus negatively influencing their performance.

CHWs in our study stated that motivation was very important in their work. Among the key motivators CHWs mentioned were incentives (financial and non-financial), capacity building / training, and recognition including from health professionals and community. These findings are similar with previous studies where motivation was majorly driven by incentives, relationship with health workers and community, capacity to provide services, and uptake of their work among others $33,39,43,44,45$. The CHWs in our study preferred financial to non-financial incentives despite Uganda having a voluntary CHW programme. It was established from our study that less than half of the CHWs $(45.3 \%)$ felt motivated in their work citing working conditions as the major cause of demotivation. These results are in agreement with those obtained from a literature review in low-and middle-income countries ${ }^{46}$. Low motivation of CHWs in our study is likely to be attributed to the health system failure to: offer incentives, provide adequate refresher trainings, supervise them frequently, and ensure availability of medicines and equipment/ span $>$ required to perform their work. To enhance performance of CHWs, their motivation needs to be considered especially in voluntary programmes such as in Uganda by not only providing them incentives but also dealing with the broader health system challenges they face. Availability of medicines and other supplies is very im- portant for the CHWs involved in iCCM to treat children under five years of age in Uganda. In our study, most CHWs had experienced stock-out of medicines (90.3\%) and other required supplies in the 6 months preceding the research. This can be attributed to the habitual stock-out of medicines in the Uganda health system due to lack of consistency in delivery schedules of supplies, and inconsideration of individual health facility needs among other factors. In addition, at times there is lack of transport for drugs from the health facilities to CHWs which further aggravates the problem. A study on poor performance of CHWs in Zambia cited irregular and unreliable supply of drugs as the most important factor for their low performance ${ }^{47}$. Availability of medicines and supplies among CHWs therefore play a critical part in their iCCM role especially in a country such as Uganda with a high prevalence of communicable diseases such as malaria and diarrhoea. Improved availability of drugs and supplies should thus be prioritized by stakeholders including National Medical Stores, $\mathrm{MOH}$, district health authorities, and health facility staff which would improve CHW performance.

One of the limitations of our study was the potential for social desirability bias given the self-reporting nature of data collection. Our study did also not consider the other roles specific to only iCCM VHTs for uniformity with their non-iCCM colleagues which could have underestimated their performance. It is also worth noting that our study did not qualitatively assess various aspects of performance such as trust by the community as well as levels of supportive supervision and communication. In addition, our study had a relatively small sample size which could have affected the categorisation of some variables and statistical power and associations. However, since the study was carried out in an entire sub-county which is a well-defined and recognised administrative structure in Uganda, the findings can relate to and inform research in similar settings. As performance is a complex variable to quantify, future studies should in addition consider examining various qualitative variables that influence performance.

\section{Conclusion}

The performance of CHWs was generally low. Receiving additional / refresher trainings, and attaining secondary 
level education and above were associated with higher performance. Motivation through incentives (financial or non-financial), official recognition and capacity building are important in the work of CHWs. To improve CHWs performance, factors such as trainings, education level during selection, as well as motivation should be considered in designing and implementing CHW programmes. In addition, health system challenges such as stock-out of medicines need to be addressed to support the work of CHWs.

\section{Competing interests}

The authors declare that they have no competing interests.

\section{Acknowledgements}

This study was conducted under a project that was supported by the Tropical Health and Education Trust (THET) as part of the Health Partnership Scheme, which was funded by the UK Department for International Development (DFID). The funder did not have any role in design of the study and collection, analysis, and interpretation of data, and in writing the manuscript. Our appreciation goes to the research assistants, community mobilisers, study participants as well as local leaders for supporting the research.

\section{Authors' contributions}

DM and LG conceptualised the study and were involved in its design, data analysis, interpretation of results and manuscript writing. TM was involved in design, data analysis, interpretation of results and manuscript writing. RN, EA and CS were involved in data analysis, interpretation of results and manuscript writing. All authors read and approved the final manuscript.

\section{References}

1. Pang T, Lansang MA, Haines A. Brain drain and health professionals: A global problem needs global solutions. BMJ 2002; 324(7336):499-500.

2. Lehmann U, Sanders D. Community health workers: what do we know about them? The state of the evidence on programmes, activities, costs and impact on health outcomes of using community health workers. Geneva: World Health Organisation, 2007.

3. Lewin SA, Dick J, Pond P, Zwarenstein M, Aja G, van Wyk B, et al. Lay health workers in primary and community health care. Cochrane Database Syst Rev 2005; (1):CD004015.

4. Kahssay H, Taylor M, Berman P. Community health workers: the way forward. Geneva: World Health Organisation, 1998.

5. Bhutta Z, Lassi Z, Pariyo G, Huicho L. Global experience of community health workers for delivery of health related Millennium Development Goals: a systematic review, country case studies, and recommendations for integration into nation health systems. Geneva: Global Health Workforce Alliance, World Health Organization, 2010.

6. Okello D, Floyd K, Adatu F, Odeke R, Gargioni G. Cost and cost-effectiveness of community-based care for tuberculosis patients in rural Uganda. The international journal of tuberculosis and lung disease : the official journal of the International Union against Tuberculosis and Lung Disease. Int J Tuberc Lung Dis 2003; 7(9 Suppl 1):S72-9.

7. Nganda B, Wang'ombe J, Floyd K, Kangangi J. Cost and cost-effectiveness of increased community and primary care facility involvement in tuberculosis care in Machakos District, Kenya. J Tuberc Lung Dis 2003; 7(9 Suppl 1):S14-20.

8. Ministry of Health, Uganda. Health Sector Strategic Plan II. Kampala 2005.

9. Ministry of Health, Uganda. Health Sector Strategic Plan I. Kampala 2001.

10. Ministry of Health, Uganda. Village health team: strategy and operational guidelines. Kampala 2010.

11. Ministry of Health, Uganda. Annual Health Sector Performance Report. Kampala 2009.

12. Ministry of Health, Uganda. Health Sector Strategic and Investment Plan 2010/11 - 2014/15: Promoting People's Health to Enhance Socio-economic Development. Kampala 2010.

13. Stoebenau K, Valente T. Using network analysis to understand community-based programs: a case study from highland Madagascar. Int Fam Plan Perspect 2003; 29(4):167-73.

14. Debpuur C, Phillips J, Jackson E, Nazzar A, Ngom P, Binka F. The impact of the Navrongo Project on contraceptive knowledge and use, reproductive preferences, and fertility. Stud Fam Plann 2002; 33(2):141-64.

15. Bhattacharyya K, Winch P, LeBan K, Tien M. Com- 
munity health worker incentives and disincentives: how they affect motivation, retention, and sustainability. Arlington (VA): Basic Support for Institutionalizing Child Survival Project (BASICS II) for the United States Agency for International Development. Arlington (VA): 2001. 16. Alam K, Tasneem S, Oliveras E. Retention of female volunteer community health workers in Dhaka urban slums: a case-control study. Health Policy Plan 2012; 27(6):477-86.

17. Gopalan SS, Mohanty S, Das A. Assessing community health workers' performance motivation: a mixed-methods approach on India's Accredited Social Health Activists (ASHA) programme. BMJ open 2012;2(5).

18. Ludwick T, Brenner JL, Kyomuhangi T, Wotton KA, Kabakyenga JK. Poor retention does not have to be the rule: retention of volunteer community health workers in Uganda. Health Policy Plan 2014; 29(3):388-95.

19. Ministry of Health, Uganda. Situation Analysis Village Health Teams Uganda Kampala 2009.

20. Ministry of Health, Uganda. National Health Policy. Kampala 2010.

21. Musoke D, Gibson L, Mukama T, Khalil Y, Ssempebwa JC. Nottingham Trent University and Makerere University School of Public Health partnership: experiences of co-learning and supporting the healthcare system in Uganda. Global Health 2016; 12:11.

22. UBOS. National population and housing census 2014 provisional results. Kampala, Uganda Bureau of Statistics 2014.

23. Crigler L, Hill K, Furth R, Bjerregaard D. 2011. Community Health Worker Assessment and Improvement Matrix (CHW AIM): A Toolkit for Improving Community Health Worker Programs and Services. Published by the USAID Health Care Improvement Project. Bethesda, MD: University Research Co., LLC (URC).

24. Wanduru P, Tetui M, Tuhebwe D, Ediau M, Okuga M, Nalwadda C, Ekirapa-Kiracho E, Waiswa P, Rutebemberwa $\mathrm{E}$. The performance of community health workers in the management of multiple childhood infectious diseases in Lira, northern Uganda - a mixed methods cross-sectional study. Glob Health Action. 2016;9:33194

25. Bagonza J, Kibira SP, Rutebemberwa E. Performance of community health workers managing malaria, pneumonia and diarrhoea under the community case management programme in central Uganda: a cross sectional study. Malar J 2014; 13:367.

26. Najafizada SAM, Labonté R, Bourgeault IL. Commu- nity health workers of Afghanistan: a qualitative study of a national program. Confl Health 2014; 8:26.

27. Kambarami RA, Mbuya MN, Pelletier D, Fundira D, Tavengwa NV, Stoltzfus RJ. Factors Associated With Community Health Worker Performance Differ by Task in a Multi-Tasked Setting in Rural Zimbabwe. Glob Health Sci Pract 2016; 4(2):238-50.

28. Ministry of Health, Uganda. A village health team booklet: Training manual. Basic information about Village Health Teams (VHTs) Kampala 2001.

29. Uganda Bureau of Statistics (UBOS). The National Population and Housing Census 2014 - Main Report, Kampala 2016.

30. Mangwi RA, Atuyambe LM, Kiguli J, Orach CG, Kolsteren P, Criel B. Use of mobile phone consultations during home visits by Community Health Workers for maternal and newborn care: community experiences from Masindi and Kiryandongo districts, Uganda. BMC Public Health 2015; 15(1):560.

31. Tumusiime DK, Agaba G, Kyomuhangi T, Finch J, Kabakyenga J, MacLeod S. Introduction of mobile phones for use by volunteer community health workers in support of integrated community case management in Bushenyi District, Uganda: development and implementation process. BMC Health Serv Res 2014; 14 Suppl 1:S2. 32. Javanparast S, Baum F, Labonte R, Sanders D. Community Health Workers' Perspectives on Their Contribution to Rural Health and Well-Being in Iran. Am J Public Health 2011;101(12):2287-92.

33. Okuga M, Kemigisa M, Namutamba S, Namazzi G, Waiswa P. Engaging community health workers in maternal and newborn care in eastern Uganda. Glob Health Action 2015; 8:23968.

34. Miller NP, Amouzou A, Tafesse M, Hazel E, Legesse $\mathrm{H}$, Degefie $\mathrm{T}$, et al. Integrated community case management of childhood illness in Ethiopia: implementation strength and quality of care. Am J Trop Med Hyg 2014; 91(2):424-34.

35. Ande O, Oladepo O, Brieger WR. Comparison of knowledge on diarrheal disease management between two types of community-based distributors in Oyo State, Nigeria. Health Educ Res 2004; 19(1):110-3.

36. Crispin N, Wamae A, Ndirangu M, Wamalwa D, Wangalwa G, Watako P, et al. Effects of Selected Socio-Demographic Characteristics of Community Health Workers on Performance of Home Visits during Pregnancy: A Cross-Sectional Study in Busia District, Kenya. Glob J Health Sci 2012; 4(5):78-90. 
37. Sharma R, Webster P, Bhattacharyya S. Factors affecting the performance of community health workers in India: a multi-stakeholder perspective. Glob Health Action 2014; 7:25352.

38. Kawakatsu Y, Sugishita T, Tsutsui J, Oruenjo K, Wakhule S, Kibosia K, et al. Individual and contextual factors associated with community health workers' performance in Nyanza Province, Kenya: a multilevel analysis. BMC Health Serv Res 2015; 15:442.

39. Kok MC, Dieleman M, Taegtmeyer M, Broerse JE, Kane SS, Ormel H, et al. Which intervention design factors influence performance of community health workers in low- and middle-income countries? A systematic review. Health Policy and Planning. Health Policy Plan 2015; 30(9):1207-27.

40. Kalyango JN, Rutebemberwa E, Alfven T, Ssali S, Peterson S, Karamagi C. Performance of community health workers under integrated community case management of childhood illnesses in eastern Uganda. Malar J 2012;11:282.

41. Kawakatsu Y, Sugishita T, Kioko J, Ishimura A, Honda S. Factors influencing the performance of community health workers in Kisumu West, Kenya. Prim Health Care Res Dev 2012; 13(4):294-300.

42. O'Donovan J, O'Donovan C, Kuhn I, Sachs SE,
Winters $\mathrm{N}$. Ongoing training of community health workers in low-income and middle-income countries: a systematic scoping review of the literature. BMJ Open. 2018;8(4):e021467.

43. Mpembeni RNM, Bhatnagar A, LeFevre A, Chitama D, Urassa DP, Kilewo C, et al. Motivation and satisfaction among community health workers in Morogoro Region, Tanzania: nuanced needs and varied ambitions. Hum Resour Health 2015;13:44.

44. Brunie A, Wamala-Mucheri P, Otterness C, Akol A, Chen M, Bufumbo L, et al. Keeping community health workers in Uganda motivated: key challenges, facilitators, and preferred program inputs. Global health, science and practice. Glob Health Sci Pract. 2014; 2(1):103-16.

45. Greenspan JA, McMahon SA, Chebet JJ, Mpunga M, Urassa DP, Winch PJ. Sources of community health worker motivation: a qualitative study in Morogoro Region, Tanzania. Hum Resour Health 2013; 11:52.

46. Kok MC, Kane SS, Tulloch O, Ormel H, Theobald $\mathrm{S}$, Dieleman M, et al. How does context influence performance of community health workers in low- and middle-income countries? Evidence from the literature. Health Res Policy Syst 2015;13:13.

47. Stekelenburg J, Kyanamina SS, Wolffers I. Poor performance of community health workers in Kalabo District, Zambia. Health Policy 2003;65(2):109-18. 